\title{
Offshore Oil and Gas Platform Transient Over-voltages from Ground Fault on Ungrounded System
}

\author{
Alvin T L, Teo ${ }^{*}$, N N Barsoum \\ Faculty of Engineering, University Malaysia Sabah, Sabah, Malaysia
}

Received August 13, 2019; Revised December 17, 2019; Accepted December 24, 2019

Copyright@2019 by authors, all rights reserved. Authors agree that this article remains permanently open access under the terms of the Creative Commons Attribution License 4.0 International License

\begin{abstract}
The High Resistance Ground was used at the oil and gas platforms because of the main reason of not having the process in the facility interrupted. There are cases where main high voltage contactor has tripped and disabled the process at satellite platforms due to the lightings module grounded. This is unacceptable to the daily production. In this paper it will discuss on the electrical distribution load flow analysis, capacitive charging system for the HRG designs and the single phase to ground fault control which is offered by the HRG systems. In the oil and gas platform, there is always a case where the ground fault occurs and causes disturbance to the process. With the 3 Generators (Solar Centaur 3125 MVA) power for the overall electrical distribution, all the equipment on the buses is prone to the faults. It has always been the challenge to control and eliminate or reduce the ground faults. The determination of the total system charging current (Ic) is important and thus determining the value of resistor that is able to limit the fault to ground. The limit of current is about 5-10A. This investigation also will compare and analyze the line to ground faults. Symmetrical components are usually widely used for the study of fault calculations.
\end{abstract}

Keywords Single Phase to Ground, High Resistance Ground, System Charging Current, Ground Fault, HRG, Resistor

\section{Introduction}

The oil and gas offshore platform at Guntong A complex has encountered multiple interruption due to the fault that occurs in the power system. This had caused the process instability and thus affected the production of oil and gas. HRG can offer continuous operation with tolerable fault in the system [1]. This is the main purpose of the HRG installation. The ground fault that happens in the power systems had caused unnecessary breakdown to the process facility. With the 4160 Vac generated from the gas turbine generator fault occurring at anytime the situation will become worst when having difficulty to detect and locate the fault in the system or equipment.HRG installation was driven by few factors as follows:

- Power continuity, when ground fault occurs it will not trip the system

- Lower repair cost because of the negligence on damage caused by the fault. Less time taken to return the faulty equipment to service

- $\quad$ Personnel safety

The offshore oil and gas platform at Guntong A complex is power with generators, electric machines, transformers and others. All of this electrical equipment is designed to accommodate all the loads in the facility (Appendix A). The power distribution for electrical equipment was built to operate under normal condition, emergency blackout and black start [1]. But due to some reasons such as ground fault that might occur, human errors, loads increases due to the current demands and the aging of equipment. To prevent or to mitigate these problems, few solutions have been considered. Importantly the safety of all the personnel on board is the top priority. Secondly, the prevention of downtime due to the fault in the electrical distribution system is important. High Resistance Ground is used to provide high reliability in the oil and gas platform. Mostly in the offshore facility environment, Line to Ground fault has the highest occurrence compared to the Line to Line and Line to Line to Ground fault. The platform has adopted the ungrounded system, because of the production continuity the High Resistance Ground installation was chosen to resolve the ground fault when it occur. Without the HRG on the ungrounded system transient overvoltage can happen. This happen when intermittent ground faults and the re-striking of fault takes place. In some cases the Line to ground voltage may cause severe damage to some of the critical equipment or electrical machines. The 
intermittent ground fault can cause severe failure in an ungrounded system. To solve this problem the High Resistance Grounding has been used with the connection of the neutral point with resistance to ground. In this paper ETAP simulator or (Electrical Transient Analysis Program) will be used to simulate the analysis. Some of the study parts will include the load flow analysis (Appendix B), short circuit analysis such as line to ground fault (Appendix C). By analyzing this functionality the fault occurrence in the circuit can be controlled and the high resistance grounding method in the system can be effectively functioning.

\section{Electrical System Distribution}

Guntong A platform was selected for its electrical distribution analysis especially to determine the fault control on the system and make recommendations for better protection on the system. Main power for the Guntong A platform supplied by 3 Solar (Centaur) gas turbine generator sets, each rated at $3125 \mathrm{KVA}$ at $4160 \mathrm{Vac}$. For normal operation, two generator sets will be run in parallel with the third set as a standby unit. Emergency power will be provided by diesel-engine generator set rated for 500KVA at 480 Vac. The engine generator set cannot be operated in parallel with the turbine generator sets but will automatically be connected to Motor Control Centre (7MC-502) if there is a primary power failure. This change over from the normal power supply to the emergency power supply will be accomplished by means of an ASCO automatic transfer switch.
The system employs high resistance grounding equipment for the generator neutrals and for the low voltage transformer neutrals [2]. Thus, no protective equipment against ground faults is installed. The High Resistance Ground must be carefully adjusted in accordance with the equipment instructions. Attention must be given to the determination of the capacitance charging current in each ground system. Without the high resistance grounding system the overall platform is ungrounded. The working principle of the HRG will discuss in detail about the system capacitive charging current.

\section{Load Flow Analysis}

Studies are carried out on the Guntong A electrical distribution system. The simulation on the load flow was done on the system when running with 2 generators (in parallel) while the other one is on standby mode. Referring to the table 1 for all the equipment report. From the report most of the main equipment such as transformer, bus bar and cable ratings is checked with the ETAP settings. In normal operation only 2 Main Oil line pump will operate, while the rest will be on standby. Supplying $4160 \mathrm{kV}$ to satellite Guntong B through submarine cable stretched approximately1-2 KM.

In emergency situation when platform gas turbine generators all are down, the diesel generator will backup and supply the essential load for the gas turbine generator to start. Such vital loads are instrument air compressor, fire water pump, diesel pump, gas turbine starter, and related vital equipment for gas turbine generators.

Table 1. Main Equipment load

\begin{tabular}{cccccccc}
\hline ID & Rating & Rated kV & $\mathrm{kW}$ & Kvar & Amp & \% PF & \% Loading \\
\hline 7MC-501 Non-Essential load & $96 \mathrm{kVA}$ & 0.48 & 95.98 & $\mathrm{n} / \mathrm{a}$ & 115.5 & 100 & 100 \\
\hline 7MC-502 Essential load & $98 \mathrm{kVA}$ & 0.48 & 97.964 & $\mathrm{n} / \mathrm{a}$ & 117.9 & 100 & 100.1 \\
\hline 7MC 901 & $167 \mathrm{kVA}$ & 0.48 & 141 & 87.616 & 202.1 & 85 & 100.6 \\
\hline Living Quarters & $70 \mathrm{kVA}$ & 0.48 & 69.974 & $\mathrm{n} / \mathrm{a}$ & 84.24 & 100 & 100.1 \\
\hline Lump1 & $167 \mathrm{kVA}$ & 0.48 & 141 & 87.616 & 202.1 & 85 & 100.6 \\
\hline Mtr1 & $190 \mathrm{KVA}$ & 4.16 & 175 & 76.235 & 26.54 & 91.71 & 100 \\
\hline Mtr2 & $190 \mathrm{KVA}$ & 4.16 & 175 & 76.235 & 26.54 & 91.71 & 100 \\
\hline Mtr3 & $190 \mathrm{KVA}$ & 4.16 & 175 & 76.235 & 26.54 & 91.71 & 100 \\
\hline Mtr4 & $220 \mathrm{KVA}$ & 4.16 & 201 & 86.729 & 30.35 & 91.8 & 100 \\
\hline Mtr5 & $220 \mathrm{KVA}$ & 4.16 & 201 & 86.729 & 30.35 & 91.8 & 100 \\
\hline To Remote Satellite GuB & $225 \mathrm{kVA}$ & 4.16 & 184 & 114 & 33.42 & 85 & 107 \\
\hline
\end{tabular}




\section{Fault Analysis Single Phase to Ground}

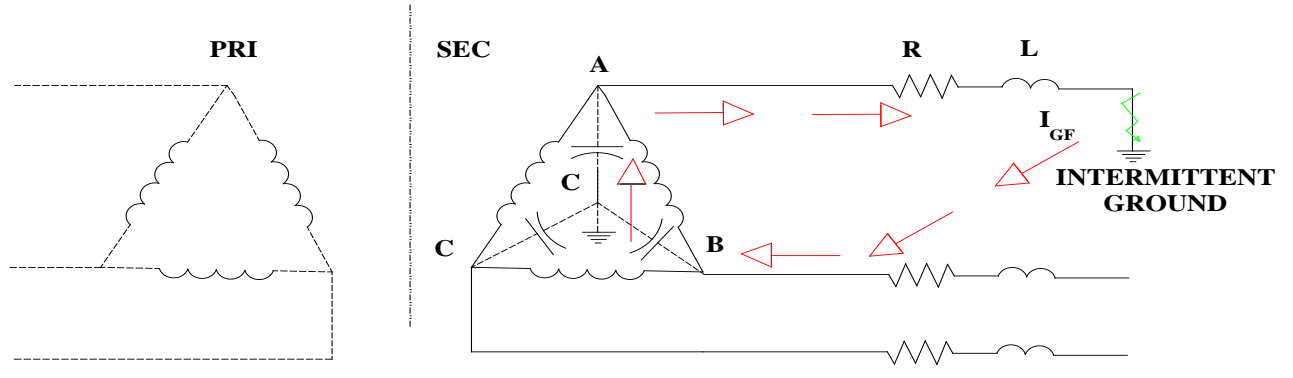

Figure 1. Single phase fault to ground with RLC circuit

$$
\mathrm{VC}=\mathrm{VR}+\mathrm{VL}+\mathrm{VGAP}
$$

Figure 1 shows that the adjacent conductors at the rate of about 1 to 2 amperes. The 1to 2 amp "charging current" is typical for $480 \mathrm{~V}$ systems. From the diagram we can see that the current that flows from linetoground is the "charging current". The charging current magnitude usually will increase when the capacitance increases. The increase in capacitance is caused by the longer cable that lay along the sea bed to the remote satellite platforms. On 480 Vrms system the typical value ranges from 1 to 2 amperes [3].From the Figure 1 we can understand the ungrounded system current flow when open delta transformer was used and the wye-connected with the capacitor representing the conductor's capacitance to ground.

The voltage developed across that capacitor is defined by Ohm's Law as:

$$
\mathrm{E}=\mathrm{IZ}=\mathrm{I}\left(\mathrm{R}+\mathrm{j} \mathrm{X}_{\mathrm{C}}\right)=\mathrm{IR}+\mathrm{jIX} \mathrm{C}
$$

Where:

$$
\begin{array}{ll}
\text { E } & \text { Voltage (Volts) } \\
\text { I } & \text { Current (Amperes) }
\end{array}
$$

Z Impedance (Ohms)

R Resistance (Ohms)

j Imaginary operator $(-1$, representing 90 phase shift for our complex/vector math equations)

$\mathrm{X}_{\mathrm{C}}$ Capacitive Reactance

$$
X_{c}=\frac{1}{2 \pi f C}
$$

From the equation above the capacitance reactance can be obtained if the value of cable capacitance is available. Where:

\section{$X_{C}$ Capacitive reactance (ohms) \\ $f$ Frequency $(\mathrm{Hz})$ \\ $C$ Capacitance (Farads)}

Current will lead the voltage when it is across the capacitor $\left(\mathrm{V}_{\mathrm{C}}\right)$ about 90 degrees. This is true because of the operator $j$ in the equation. Whenever the current crosses through the path at zero point, the voltage across the capacitor will be maximum. Table 2 shows the line to ground fault at $V_{a}$ phase and the increase of $73 \%$ on the phase $\mathrm{V}_{\mathrm{b}}$ and $\mathrm{V}_{\mathrm{c} \text {. }}$. 
Table 2. Line to Ground Fault

\begin{tabular}{|c|c|c|c|c|}
\hline \multicolumn{2}{|c|}{ Contribution } & \multicolumn{3}{|c|}{ Line to Ground Fault } \\
\hline From Bus & To Bus & \multicolumn{3}{|c|}{$\%$ Voltage at or from Bus } \\
\hline ID & ID & $\mathrm{V}_{\mathrm{a}}$ & $\mathrm{V}_{\mathrm{b}}$ & $\mathrm{V}_{\mathrm{c}}$ \\
\hline Bus 4 & All & 0.00 & 173.21 & 173.21 \\
\hline Bus 18 & Bus 4 & 0.00 & 173.21 & 173.21 \\
\hline Bus 14 & Bus 4 & 100.00 & 100.00 & 100.00 \\
\hline Bus 15 & Bus 4 & 100.00 & 100.00 & 100.00 \\
\hline Mtr 1 & Bus 4 & 0.00 & 173.21 & 173.21 \\
\hline Mtr 2 & Bus 4 & 0.00 & 173.21 & 173.21 \\
\hline Mtr 3 & Bus 4 & 0.00 & 173.21 & 173.21 \\
\hline Mtr 4 & Bus 4 & 0.00 & 173.21 & 173.21 \\
\hline Mtr 5 & Bus 4 & 0.00 & 173.21 & 173.21 \\
\hline Bus 8 & Bus 6 & 100.00 & 100.00 & 100.00 \\
\hline Gen 2 & Bus 2 & 0.00 & 173.21 & 173.21 \\
\hline Gen 1 & Bus 1 & 0.00 & 173.21 & 173.21 \\
\hline To Remote Satellite GuB & Bus 18 & 0.00 & 173.21 & 173.21 \\
\hline 7MC-901 & Bus 16 & 100.00 & 100.00 & 100.00 \\
\hline Lump 1 & Bus 17 & 100.00 & 100.00 & 100.00 \\
\hline Living Quarters & Bus 13 & 100.00 & 100.00 & 100.00 \\
\hline 7MC-502 Essential load & Bus 12 & 100.00 & 100.00 & 100.00 \\
\hline Bus 1 & Bus 4 & 0.00 & 173.21 & 173.21 \\
\hline Bus 2 & Bus 4 & 0.00 & 173.21 & 173.21 \\
\hline Bus 6 & Bus 4 & 0.00 & 173.21 & 173.21 \\
\hline Bus 4 & Bus 20 & 0.00 & 173.21 & 173.21 \\
\hline Bus 16 & Bus 14 & 100.00 & 100.00 & 100.00 \\
\hline Bus 17 & Bus 15 & 100.00 & 100.00 & 100.00 \\
\hline Bus 16 & Bus 17 & 100.00 & 100.00 & 100.00 \\
\hline Bus 10 & Bus 8 & 100.00 & 100.00 & 100.00 \\
\hline Bus 12 & Bus 10 & 100.00 & 100.00 & 100.00 \\
\hline Bus 13 & Bus 10 & 100.00 & 100.00 & 100.00 \\
\hline
\end{tabular}

\section{High Resistance Ground Charging Capacitance Current}

The magnitude of the zero sequence charging current will be determined by the associated system components in the system of line to ground capacitance. For a correct selection of the High Resistance Groundingresistor value the value of system charging current is very important. High Resistance Grounding will depend on the system capacitance charging current[4]. In most of the networks the transformers ground capacitance is always negligible. The reasons are because the shielding effects of the internal core with all the adjacent windings, the large gap or space of the windings and core may limit the ground capacitance to a minimum value. The capacitance of cable is greater if compared to the open wire lines. Besides that the length of the cable can contribute to the significant rise of the capacitance to ground [5]. In detail the capacitance of the cable attributes to the types, conductor size and the insulation of the cable construction. All the equipment such as the induction motors and synchronous motors is the main cause of the total system capacitance to ground. In comparison at the same rating, the lower voltage machines have the higher capacitance because of the lesser insulation in reference to ground and the larger conductor and also the bigger slot surface area. In the phase of designing the High Resistance Grounding, one of the important parts is to determine the system charging current. This charging current will affect the High Resistance Grounding resistor value at the neutral connection. Charging current ranges in between 5 to $10 \mathrm{amp}$ for the medium voltage (4160).

\section{High Resistance Ground Design}

High resistance ground must be able to limit the ground fault to $10 \mathrm{~A}$ as it was intended to the power system. It is important to determine the value of the resistor that suits to the system. By using the external ungrounded power supply this method will be used under the energized system (Figure 2). The system charging current can be calculated 
when the existing neutral system is offset by the external power supply. Figure 2 shows the electrical circuit with the injected variable power supply to the system neutral. A simple representation of the whole circuit can be simplified in the Figure 3 below. The variable auto transformer circuit installed in parallel loop with the system charging current in reference to the grounding [6].

To obtain the variable current corresponding to the parallel capacitance of all the 3 phases it must be plotted to a graph as shown in figure 4 . When the ratio of $k$ becomes constant, then at this time the system neutral has been displaced by the injected voltage away from the ground figure (4). At this point onwards the current has flowed through the parallel capacitance at maximum peak value. This ratio $\mathrm{k}$ will represent the $\left(\mathrm{X}_{\mathrm{CO}} / 3\right)$, and this is the one third of the line to ground capacitance reactance $X_{\mathrm{CO}}$. The system charging can be obtained and calculated when the capacitance reactance value in the system is given [7].

1-2

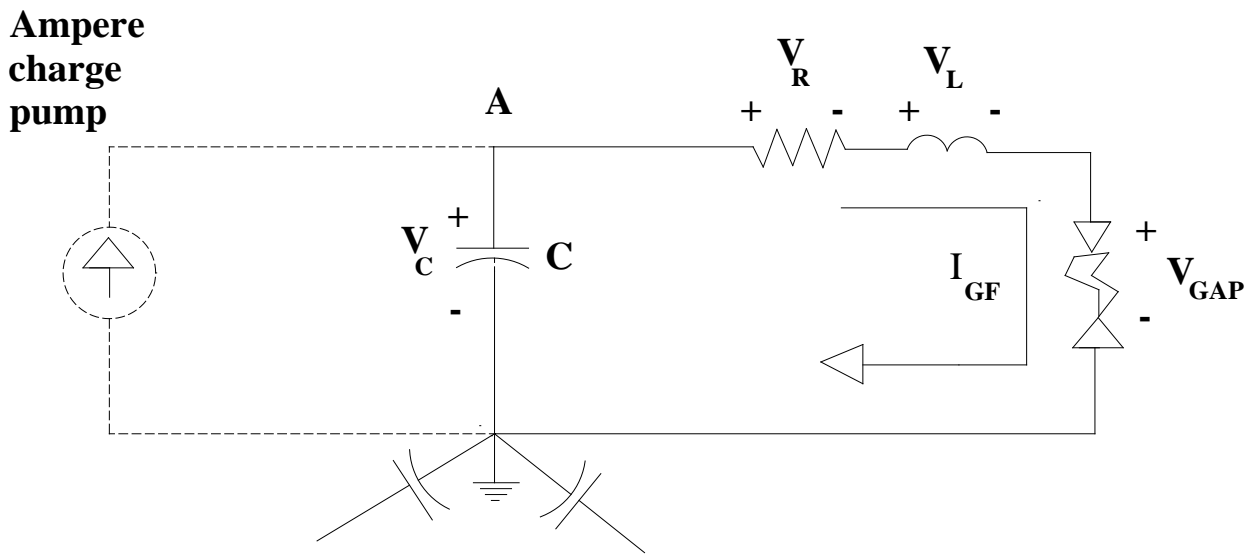

Figure 2. Single phase fault to ground and schematic of line to ground charging current.

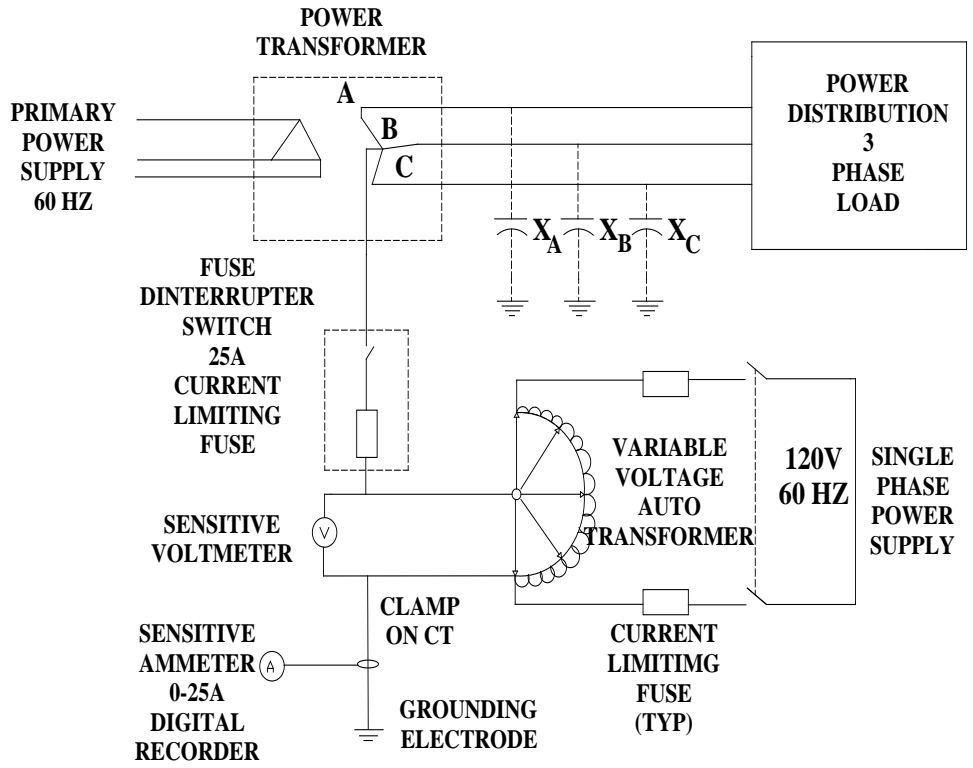

Figure 3. Variable voltage was used at the system neutral 


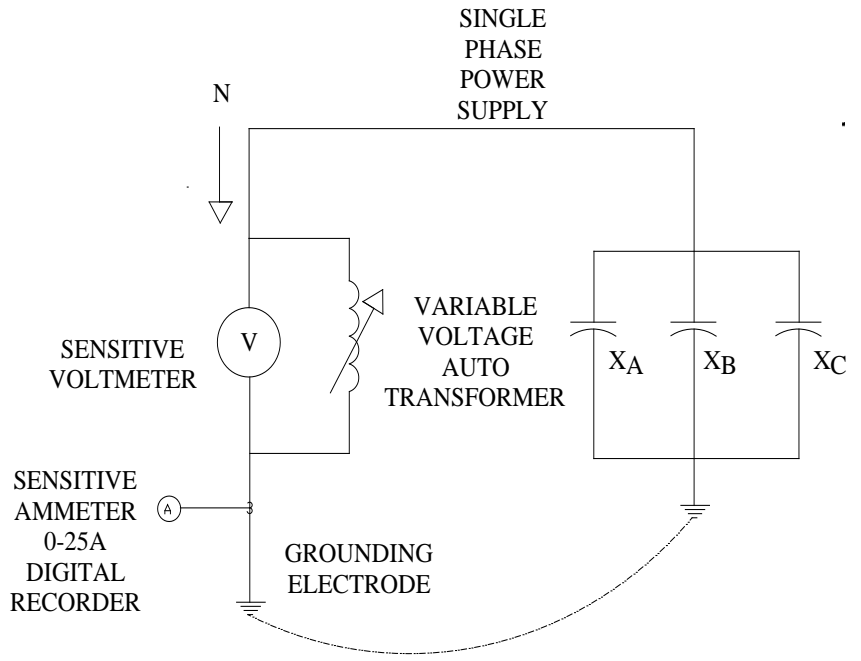

Figure 4. Equivalent electrical circuit of Figure 2

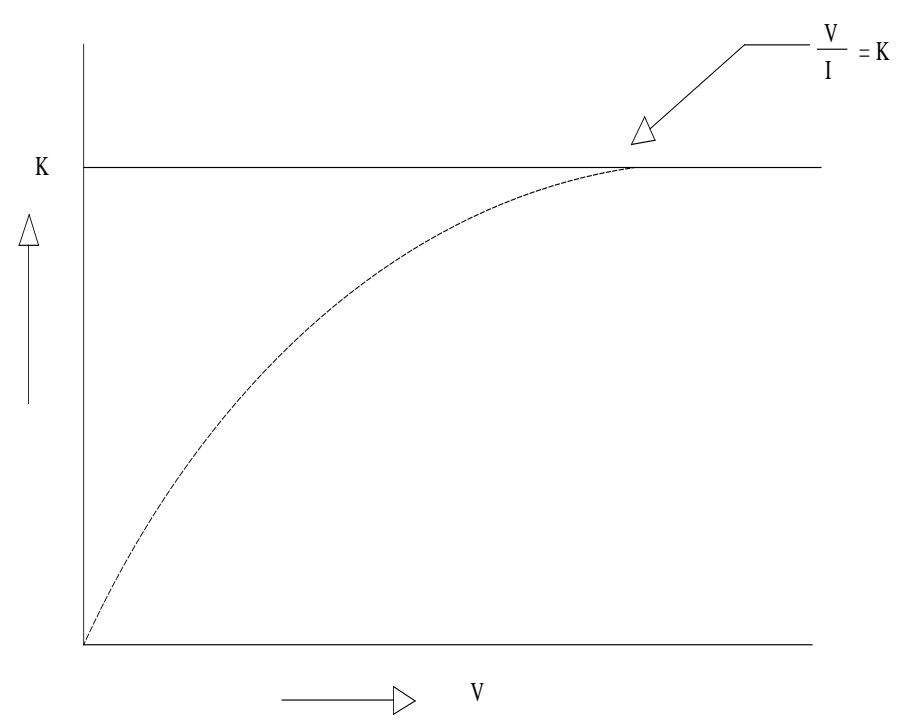

Figure 5. Derivation of $(\mathrm{k})$ which is $\left(\mathrm{X}_{\mathrm{CO}} / 3\right)$.

\section{Conclusions}

From the simulation of the ETAP the changing load of the pump and other main electrical equipment can be seen. All the essential power that meant for the vital load at platform during emergency is very critical during power failure. In the power system any fault such as single phase to ground must not interrupt the system because of the
High Resistance Ground unit that will limit the fault to tolerable fault 10A. The fault study done on the power system shows that the overvoltage occurs when single phase to ground strikes on the bus 4 . This can be prevented by the HRG installation because the ungrounded system will not have transient overvoltage if the current is allowed to flow through the ground fault at the value that is larger than the system charging current. 


\section{Appendix A: Guntong A platform electrical power distribution}

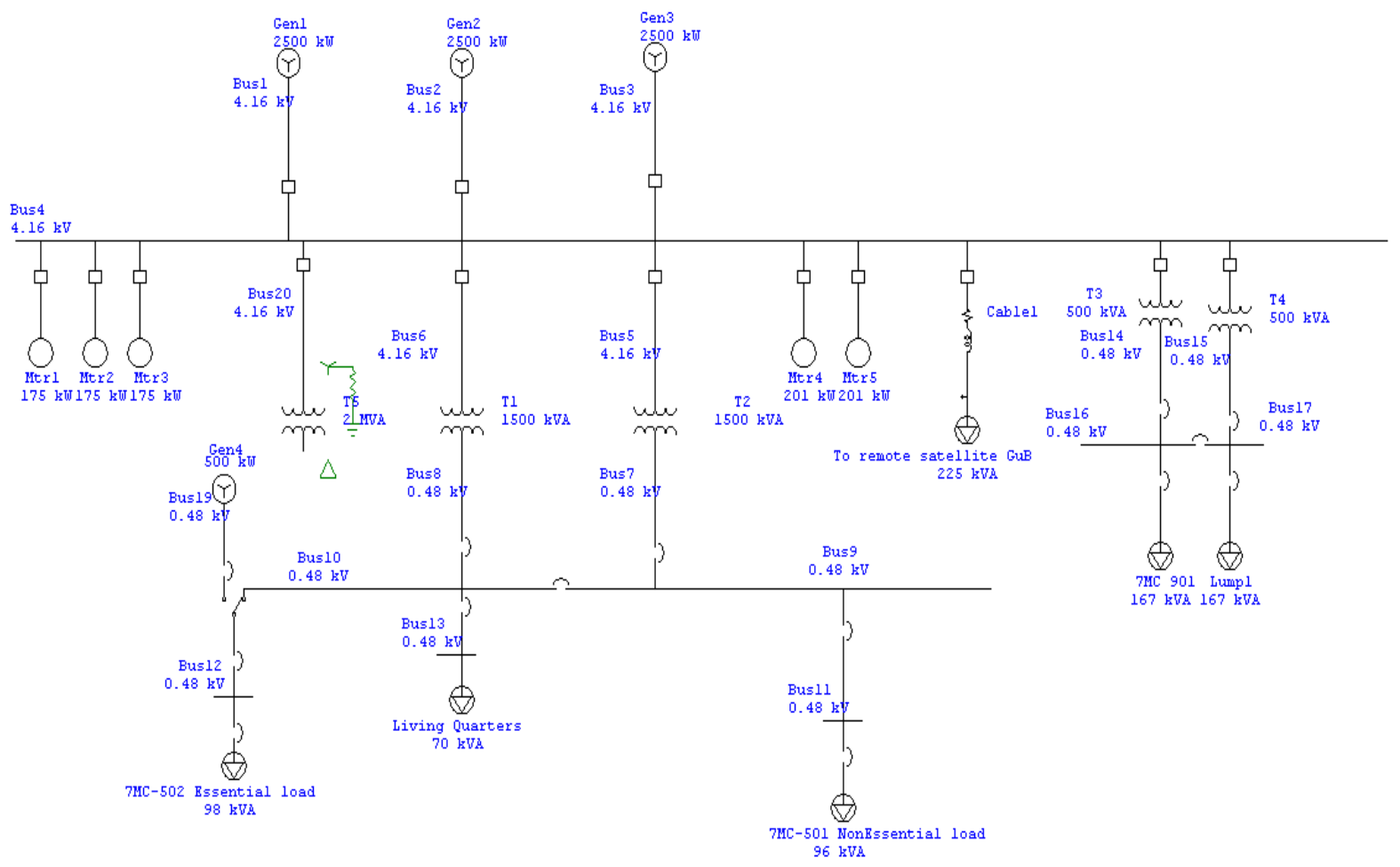

\section{Appendix B: Load flow analysis}

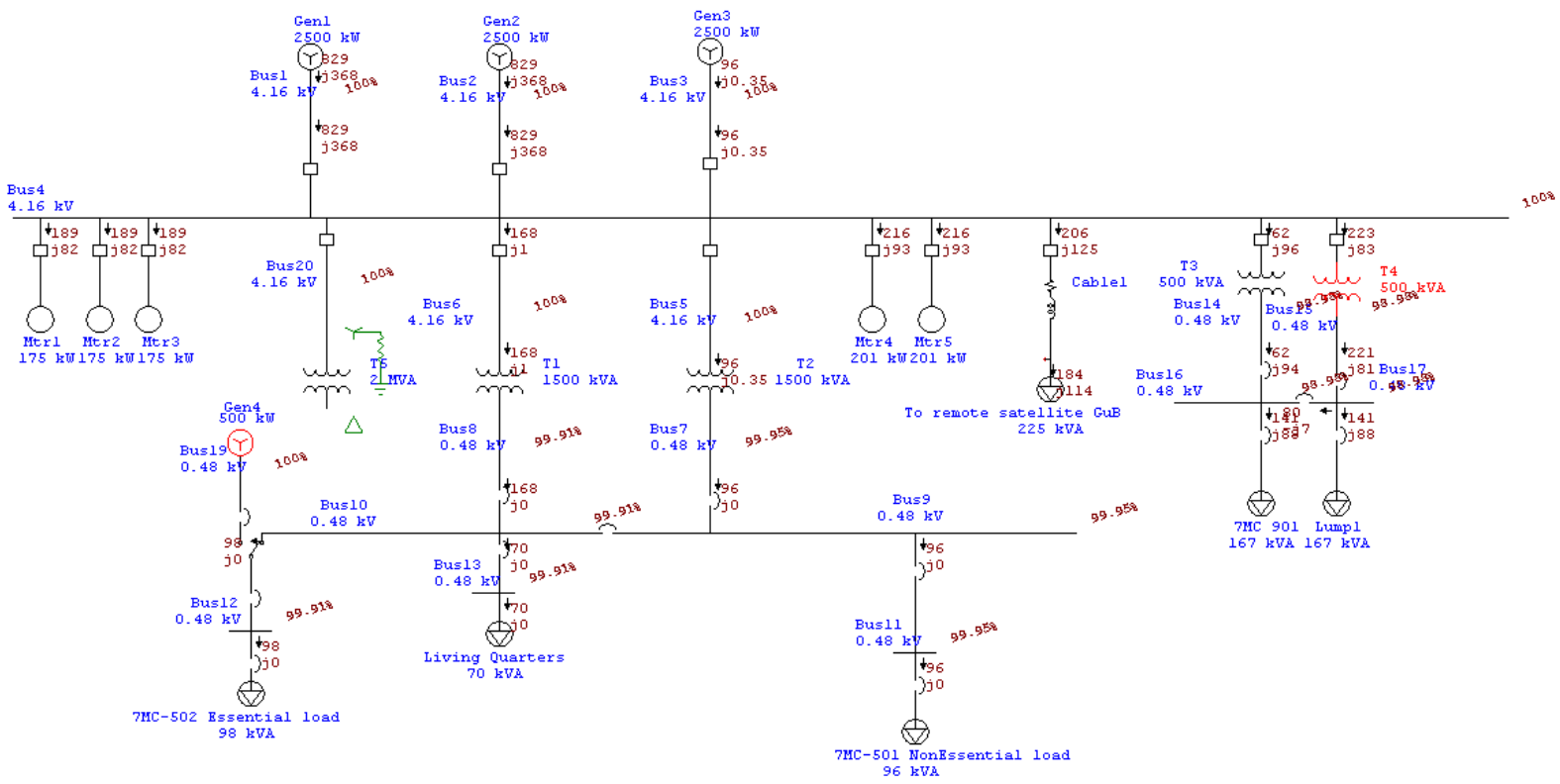




\section{Appendix C: Line to ground fault simulation.}

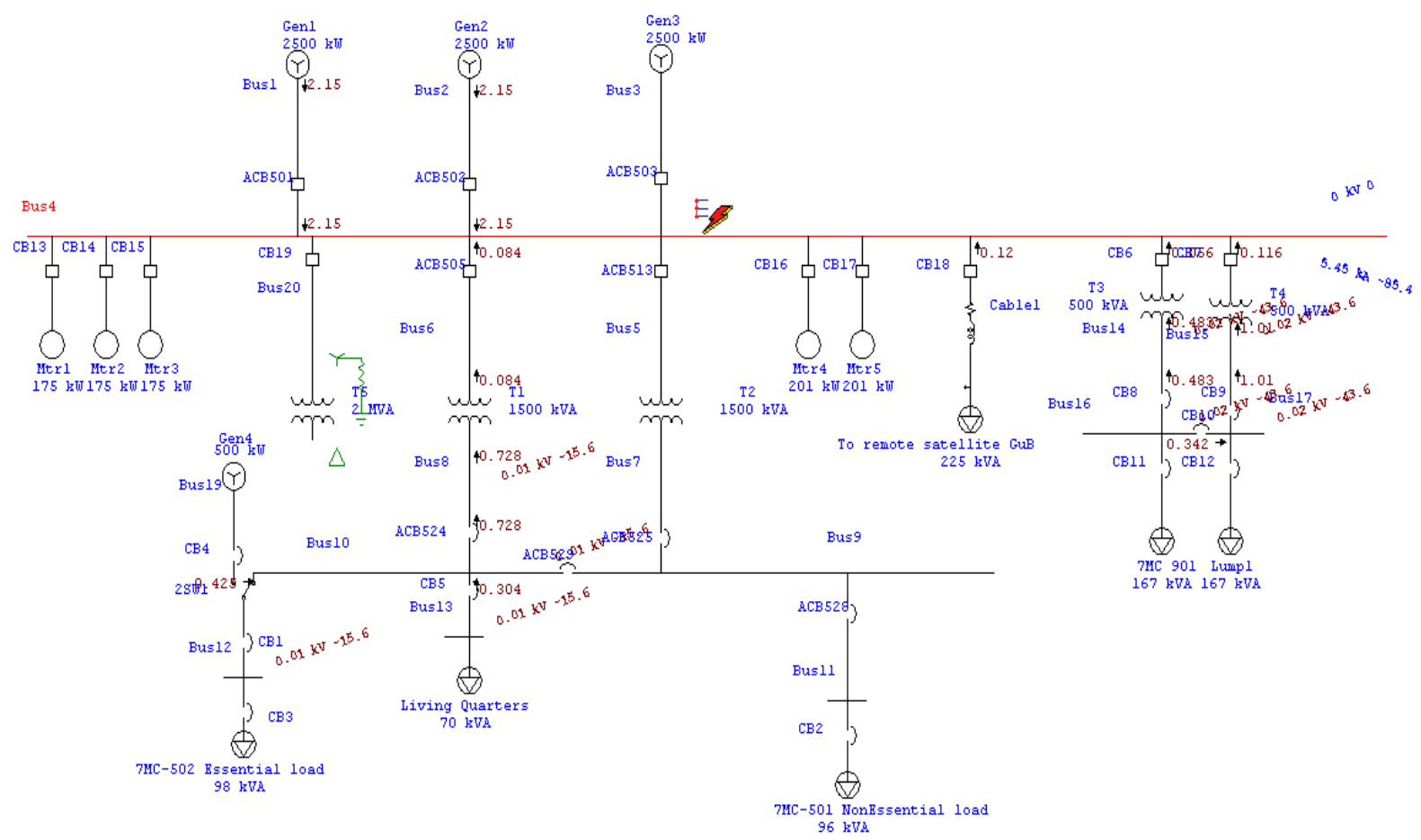

\section{REFERENCES}

[1] K. I. Wong, K. H. Law, T. U. Siaw, C. K. Wong and N. N. Barsoum, "Analysis of Electrical Distribution System for Offshore Oil and Gas Platform," 2019 IEEE Asia Power and Energy Engineering Conference (APEEC), Chengdu, China, 2019, pp. 302-306.

[2] L. J. Kingrey, R. D. Painter and A. S. Locker, "Applying High-Resistance Neutral Grounding in Medium-Voltage Systems," in IEEE Transactions on Industry Applications, vol. 47, no. 3, pp. 1220-1231, May-June 2011.

[3] Eaton "Transient Over-voltages on Ungrounded Systems from Intermittent Ground Faults,” White paper.

[4] J. P. Nelson, D. Burns, R. Seitz and A. Leoni, "The grounding of marine power systems: problems and solutions," Fifty-First Annual Conference 2004 Petroleum and Chemical Industry Technical Conference, 2004., San Francisco, CA, USA, 2004, pp. 151-161.

[5] J. Sottile, S. J. Gnapragasam, T. Novak and J. L. Kohler, "Detrimental Effects of Capacitance on High-Resistance

[6] Grounded Mine Distribution Systems," in IEEE Transactions on Industry Applications, vol. 42, no. 5, pp. 1333-1339, Sept.-Oct. 2006.

[7] D. Paul, P. E. Sutherland and S. Panetta, "A novel method of measuring inherent power system charging current," 2011 IEEE Industrial and Commercial Power Systems Technical 